Júlio César de SOUZA JÚNIOR ${ }^{1}$

Zelinda Maria Braga

HIRANO ${ }^{1,2}$

Fernando Dias de ÁVILAPIRES $^{3}$

Gladys Rosane Thomé

VIEIRA ${ }^{2}$

\section{Correspondência para:}

Rua Rio de janeiro 401, Dos Estados, 89130-000 - Indaial, SC - Brasil (47) 3333878; juliocesar_jr@terra.com.br\&gt; juliocesar_jr@terra.com.br

Recebido para publicação: 10/05/2007 Aprovado para publicação: 24/04/2008

\title{
Nota sobre infecção por Salmonella sp. e Shigella sp. em bugios-ruivos, Alouatta clamitans Cabrera, 1940 (Primates: Atelidae) mantidos em cativeiro
}

\author{
1 - Centro de Pesquisas Biológicas de Indaial, Indaial-SC \\ 2 - Departamento de Ciências Naturais da Fundação Universidade Regional \\ de Blumenau, Blumenal-SC \\ 3 - Programa de Pós-graduação em Saúde Pública da Universidade Federal \\ de Santa Catarina, Florianópolis-SC
}

\section{Resumo}

Amostras de fezes de bugios-ruivos cativos foram investigadas quanto a presença de Salmonella sp. e Shigella sp. O padrão de sensibilidade a antibióticos foi testado. Este é o primeiro relato de infecção assintomática por Salmonella sp. nesta espécie. Não foi detectada infecção por Shigella sp. Destaca-se a importância de investigação em animais submetidos a translocação ou a reintrodução e a necessidade de inquéritos periódicos em populações cativas a fim de se evitar agravos ocupacionais.

Primatas não-humanos são reservatórios de uma grande variedade de agentes infecciosos com potencial implicação à Saúde Pública. ${ }^{1}$ A manutenção em cativeiro aumenta o risco de exposição humana a estes agentes, estabelecendo assim novas relações entre hospedeiros e parasitas, e novos nichos ecológicos na cadeia de transmissão das doenças. $^{2}$

Os bugios são conhecidos como animais de difícil manutenção em cativeiro pela falta de adaptação à dieta e pela susceptibilidade a doenças. Embora existam muitos estudos sobre a fauna parasitológica ${ }^{3}$ pouco se sabe sobre sua microbiota bacteriana e seu potencial patogênico ${ }^{4}$.

Objetivou-se neste estudo investigar a infecção por Salmonella sp. e Shigella sp. na subespécie Alouatta clamitans, e seu padrão de sensibilidade a antimicrobianos.

Durante o período de 20/09/2006 a 04/10/2006, foram colhidas amostras fecais de 32 exemplares (14 machos adultos, um macho subadulto, cinco machos juvenis, seis fêmeas adultas, duas fêmeas subadultas e duas fêmeas juvenis) mantidos no criadouro científico do Centro de Pesquisas Biológicas de Indaial no Estado de Santa

\section{Catarina.}

O material foi analisado no Laboratório de Microbiologia da Universidade Regional de Blumenau, onde se observou o aspecto das fezes e confeccionaram-se esfregaços em lâminas para bacterioscopia pelo método de Gram. A partir de uma diluição em salina tamponada, realizaram-se as semeaduras por esgotamento em meios seletivos e diferenciais, ágar Mac Conkey e ágar SS, e a encubação em aerobiose a $37^{\circ} \mathrm{C}$, durante 18 24 horas. As amostras foram também diluídas em caldo selenito para enriquecimento de Salmonella, e após 18 horas foram repicadas em placas de ágar Mac Conkey, sendo incubadas nas mesmas condições. $^{5}$

As colônias lactose negativas, suspeitas de Shigella sp. e de Salmonella sp., foram submetidas a provas bioquímicas, utilizando o meio de Rugai com lisina e o ágar citrato de Simmons. As cepas bacterianas suspeitas, identificadas bioquimicamente, foram submetidas ao teste de aglutinação em lâmina, utilizando-se anti-soros específicos.

Realizou-se o teste de sensibilidade aos antimicrobianos (TSA), pelo método de disco difusão de Kirby-Bauer para a cepa 
com sorologia positiva. Esta foi diluída em caldo Mueller-Hinton, na concentração 0,5 da escala de Mac Farland, e semeada em placas de ágar Mueller-Hinton. Os discos impregnados com os antimicrobianos foram colocados na superfície do meio, incubados a $35^{\circ} \mathrm{C}$ por $16-18$ horas $^{6,7}$. Foram medidos os diâmetros dos halos de inibição de crescimento e comparados com a tabela fornecida pelo fabricante $\left(\operatorname{Laborclin}^{\circledR}\right)$, para verificação da sensibilidade.

Dos 32 animais pesquisados, isolouse Salmonella sp. da amostra fecal, de aspecto normal, de um macho adulto clinicamente sadio. O mesmo é oriundo de ambiente natural e há sete anos é mantido em cativeiro. Não foi detectada infecção por Shigella sp.

O TSA demonstrou a sensibilidade da cepa aos antimicrobianos: ácido nalidíxico, amicacina, aztreonam, cefotaxima, cefoxitina, ciprofloxacina, gentamicina, norfloxacina e sulfazotrim, sendo resistente apenas a ampicilina e a cefalotina.

$\mathrm{Na}$ bacterioscopia pela coloração de Gram foi observada uma microbiota mista, com predomínio de bacilos Gram-negativos em todas as fezes examinadas. $\mathrm{Na}$ amostra positiva para Salmonella sp., o resultado foi semelhante às demais e não se observaram leucócitos fecais, evidenciando o estado de portador assintomático do animal.

Salmonella Typhimurium já foi associada a abscesso subcutâneo em Alouatta villosa ${ }^{8}$. Este é o primeiro relato de infecção assintomática por Salmonella sp. em Alouatta clamitnas.

Sinais clínicos podem ocorrer de acordo com o número de organismos infectantes, com o estado imunológico e com fatores adversos como enfermidades intercorrentes.

O contato com o homem, com animais domésticos e sinantrópicos, e a contaminação de alimentos, têm sido relatadas como as principais vias de transmissão para primatas não-humanos cativos. ${ }^{10}$

Não se descarta a hipótese de que outros animais da coleção possam albergar o microrganismo, visto que o estudo restringiu-se a avaliar apenas uma amostra, $\mathrm{e}$ como no homem, há a possibilidade de eliminação de bactérias nas fezes de forma intermitente.

Destaca-se a importância de inquéritos rotineiros em populações cativas a fim de prevenir agravos ocupacionais, e sugere-se que esta investigação seja incluída em protocolos de avaliação sanitária de bugios-ruivos submetidos a programas de translocação e de reintrodução.

\section{Note about Salmonella sp. and Shigella sp. infections in southern brown howler monkeys, Alouatta clamitans Cabrera, 1940 (Primates: Atelidae) on captivity}

\section{Abstract}

Fecal samples of captive souther brown howler monkeys were screened for the presence of Salmonella sp. and Shigella sp. The sensibility for antibiotics was also measured. This is the first report of asymptomatic infection by Salmonella sp. in this specie. Shigella sp. infection was not detected. Screening for this bacteria should be performed during translocation and reintroduction programs. We recommend periodic investigations to prevent occupational hazard on captivity.
Key words: Salmonella sp. Shigella sp. Brown howler monkey. Captivity.

\section{Referências}

1 FIENNES, R. N.; CARRINGTON, R.; MATTEWS, L. $\mathrm{H}$. Zoonoses of primates. The epidemiology and ecology of simian diseases in relation to man. Itaca: Cornell University Press, 1967. 190 p.

2 CORRÊA, S. H. R.; PASSOS, E. C. Wild animals and public health. In: FOWLER, M. E.; CUBAS, Z. S. 
Biology, medicine, and surgery of South American wild animals. Ames: lowa University Press, 2001. p. 493499.

3 STUART, D. M.; PENDERGAST, V.; RUMFELT, S.; GREENSPAN, L.; GLANDER, K.E; CLARKE, M. R. Parasites of wild howlers (Alouatta spp.). International Journal of Primatology, v. 19, n. 3, p. 493-512, 1998.

4 CORONADO, M. M. G.; CAVALLINI, E. R.; CONTRERAS, G. R.; PORRAS, R. S; ESPELETA, G. G. Flora bacterial oral y su perfil de sensibilidad a antibióticos en monos da Costa Rica (Alouatta palliata y Ateles geoffroyi). Neotropical Primates, v. 12, n. 1, p.12-30, 2004.

5 KONEMAN, E. W.; ALLEN, S. D.; JANDA, W. M.; SCHRECKENBERGER, P. C.; WINN Jr., W. C. Diagnóstico microbiológico: texto e atlas colorido. 5. ed. Rio de Janeiro: Medsi, 2001. 464 p.

6 NATIONAL COMMITTEE FOR CLINICAL LABORATORY STANDARD. Performance standards for antimicrobial disk susceptibility testing. 7. ed. Wayne, 2000. (Approved standard: M2-A7, supplement M100-S9).

7 NATIONAL COMMITTEE FOR CLINICAL LABORATORY STANDARD. Methods for dilution antimicrobial susceptibility tests for bacteria that grow aerobically. 5. ed. Wayne, 2000. (Approved standard: M7-A5).

8 KOURANY, M.; ROSSAN, R. N. A subcutaneous abcess associated with Salmonella typhimurium in black howler monkey (Alouatta villosa). Laboratory Animal Science, v. 21, n. 30, p. 412-414, 1971.

9 CORRÊA, W. M.; CORRÊA, C. N. M. Paratifo em geral. In: CORRÊA, W. M. Enfermidades infecciosas dos mamíferos domésticos. 2. ed. Rio de Janeiro: Medsi, 1992. p. 163-167.

10 FORD, A. C. Salmonellosis, simians and man. Morbidity and Mortality Weekly Report, v. 5, p. 1-11, 1971 